\title{
PENGARUH LEVERAGE, KEPEMIIKAN INSTITUSIONAL DAN UKURAN PERUSAHAAN TERHADAP MANAJEMEN LABA
}

\author{
Inge Lengga Sari Munthe (ingemunthe@yahoo.com) \\ Universitas Maritim Raja Ali Haji (UMRAH)
}

\begin{abstract}
ABSTRAK
Topik penelitian ini adalah mengenai pengaruh Leverage, Kepemilikan Institusional dan Ukuran perusahaan terhadap Manajemen Laba. Objek yang diteliti adalah perusahaan subsektor tekstil dan garment yang terdaftar di Bursa Efek Indonesia. Tahun penelitian adalah dari 2014 sampai 2016. Terdapat 16 sampel perusahaan yang dipakai dalam penelitian ini. Tehnik penelitian dengan menggunakan analisa regresi. Hasil penelitian adalah secara simultan, berpengaruh terhadap manajemen laba. Sedangkan secara parsial, hanya ukuran perusahaan saja yang berpengaruh terhadap manajemen laba.
\end{abstract}

\section{PENDAHULUAN}

Manajemen laba adalah topik yang sangat hangat saat ini. Indikasi melakukan manajemen laba dilihat dari Discretionary Accrual dari Modified Model Jones. Bila manajemen terlalu banyak, maka dapat menurunkan kemampuan investor dalam mengartikan laba sekarang. Manajemen laba juga berguna menjadi media komunikasi yang baik bagi investor. Leverage adalah rasio hutang. Bagi rasio hutang, bila nilainya tinggi, maka indikasi bagi perusahaan itu kurang bagus. Salah satu cara memaksimalkan laba dalam manajemen laba adalah dengan menghindari dari pelanggaran kontrak hutang jangka panjang.Kepemilikan institusional adalah proporsi kepemilikan secara institusi terhadap suatu perusahaan. Semakin besar dari kepemilikan institusi, maka semakin kuat pengendalian terhadap perusahaan. Ukuran perusahaan adalah besar atau kecilnya suatu perusahaan. Umumnya ukuran perusahaan diukur dengan total aset suatu perusahaan.

Berdasarkan pendahuluan diatas,maka rumusan masalah dalam pelitian terdiri dari : 1) Apakah Leverage berpengaruh terhadap manajemen laba ? 2) Apakah Kepemilikan Institusional berpengaruh terhadap manajemen laba ?, 3) Apakah Ukuran Perusahaan berpengaruh terhadap manajemen laba ? 4)Apakah leverage, kepemilikan institusional dan ukuran peusahaan berpengaruh terhadap manajemen laba?

\section{LANDASAN TEORI}

\section{Manajemen Laba}

Manajemen laba adalah pilihan oleh manajer terhadap kebijakan akuntansi atau tindakan nyata yang mempengaruhi laba sehingga tujuan penghasilan yang dilaporkan tercapai. Bila dilihat dari perspektif laporan keuangan, manajemen laba dibuat untuk menghindari pelaporan kerugian atau untuk memenuhi ramalan pendapatan dari analis. Harapan dari tindakan ini adalah untuk menghindari rusaknya reputasi dan reaksi negatif harga saham yang mengikuti dengan cepat kegagalan dari ekspektasi investor (Aryati, 2017). 
Hubungan keagenan antara pemegang saham dan manajer adalah pemegang saham mendelegasikan pengambilan keputusan kepada manajer. Sebagai manajer secara moral bertanggung jawab untuk mensejahterakan pemilik. Sebagai kompensasi, maka manajer mendapat kompensasi dari kontrak dan apa yang telah dilakukannya itu. Terdapat dua kepentingan berbeda dari dalam perusahaan dimana masing-masing pihak berusaha untuk mencapai atau mempertahankan tingkat kemakmuran yang dikehendaki (Ujiyantho, 2007).

Terdapat 4 pola manajemen laba yaitu (Aryati, 2017):

1. Taking $A$ Bath. Teknik ini mengakui adanya biaya-biaya pada periode yang akan datang dan kerugian periode berjalan ketika keadaan buruk yang tidak menguntungkan tidak bisa dihindari pada periode berjalan. Konsekuensinya, manajemen "menghapus" beberapa asset, membebankan perkiraan-perkiraan yang mendatang, dan melakukan "clear the decks".

2. Income Minimization. Cara ini dilakukan pada saat profitabilitas perusahaan sangat tinggi dengan maksud agar tidak mendapat perhatian secara politis. Kebijakan yang diambil dapat berupa penghapusan (write offs) atas barang modal dan asset tak berwujud, pembebanan pengeluaran iklan, riset dan pengembangan yang cepat, memilih metode succesful-effort untuk biaya eksplorasi gas dan minyak bumi, dan sebagainya.

3. Income Maximization. Maksimalisasi laba dimaksudkan untuk memperoleh bonus yang lebih besar, dimana laba yang dilaporkan tetap dibawah cap. Juga untuk menghindar dari pelanggaran atas kontrak hutang jangka panjang (debt covenant). Cara ini dapat ditempuh dengan mengubah metode atau asumsi akuntansi ke yang lebih liberal.

4. Income Smoothing. Hal ini dilakukan dengan meratakan laba yang dilaporkan untuk tujuan pelaporan eksternal, terutama bagi investor karena pada umumnya investor lebih menyukai laba yang relatif stabil.

\section{Leverage}

Perusahaan dalam mendanai perusahaannya memiliki beberapa sumber dana. Sumber dana itu dapat diperoleh dari pinjaman atau modal sendiri. Dalam hal ini, leverage ratio ( rasio solvabilitas) merupakan rasio yag digunakan untuk mengukur sejauh mana aktiva perusahaan dibiayai dengan utang. Artinya besarnya jumlah utang yang digunakan perusahaan untuk membiayai kegiatan usahanya jika dibandingkan dengan menggunakan modal sendiri (Kasmir, 2008).

Rasio leverage atau solvabilitas merupakan rasio yang digunakan untuk mengukur seberapa besar beban utang yang harus ditangung perusahaan dalam rangka pemenuhan aset. Dalam arti luas, rasio ini digunakan untuk mengukur kemampuan perusahaan dalam memenuhi seluruh kewajibannya, baik kewajiban jangka pendek maupun kewajiban jangka panjang (Hery, 2016).

Diantara beberapa rasio leverage, ada rasio utang terhadap aset (Debt to Asset Ratio). Rasio ini mengukur perbandingan antara total utang dengan total aset.Rasio ini digunakan untuk mengukur seberapa besar aset perusahaan dibiayai oleh utang. Apabila rasio utang terhadap aset adalah tinggi maka hal ini tentu saja akan mengurangi kemampuan perusahaan untuk memperoleh tambahan pinjaman dari kreditor. Dikhawatirkan bahwa perusahaan tidak mampu melunasi utangnya dengan total aset yang dimilikinya (Hery,2016).

\section{Kepemilikan Institusional}

Kepemilikan institusional merupakan kepemilikan saham oleh pihak institusi atau lembaga, seperti perusahaan, bank, asuransi, dana pensiun, aset management dan kepemilikan institusi 
lainnya. Institusi menguasai mayoritas saham, karena mereka memiliki sumber dana yang paling besar dibangingkan dengan pemegang saham lainnya (Susanti, 2015).

Kepemilikan institusional akan mendorong pengingkatan pengawasan yang lebih optimal. Semakin besar kepemilikan institusi, maka akan semakin besar kekuatan suara dan dorongan dari institusi untuk mengawasi manajemen. Akibatnya akan memberikan dorongan yang lebih besar untuk mengoptimalkan perusahaan (Kusumawardhani, 2009).

\section{Ukuran Perusahaan}

Ukuran perusahaan menunjukkan besar atau kecilnya perusahaan. Ukuran perusahaan dapat dinyatakan dalam tiga bentuk, yaitu :

1) Total Aset.Semakin besar aset, semakin banyak modal yang ditanam.

2) Total Penjualan. Semakin banyak penjualan, semakin banyak perputaran uang.

3) Kapitalisasi Pasar.Semakin besar kapitalisasi pasar, maka semakin besar perusahaan dikenal masyarakat.

Dari ketiga variabel pengukuran perusahaan, umumnya penelitian menggunakan total aset dalam pengukurannya. Hal ini disebabkan nilai aset relatif lebih stabil dibandingkan dengan penjualan dan kapitalisasi pasar dalam pengukuran perusahaan (Sudarmadji dan Sularto,2007).

\section{Pengembangan Hipotesis}

Perusahaan yang mempunyai rasio leverage tinggi akibat besarnya jumlah utang dibandingkan dengan aset yang dimiliki perusahaan, diduga melakukan manajemen laba. Hal ini karena perusahaan terancam default yaitu tidak dapat memenuhi kewajiban pembayaran utang pada waktunya (Trisnawati,2009). Manajemen diduga akan memilih prosedur akuntansi yang meningkatkan aktiva, mengurangi utang dan meningkatkan pendapatan dengan tujuan untuk menghindari pelanggaran debt-covenant (Nanok,et.al).

\section{Hipotesis 1 : Diduga leverage berpengaruh terhadap manajemen laba.}

Investor institusional diduga lebih mampu untuk mencegah terjadinya manajemen laba dibanding dengan investor individual. Investor institusional dianggap lebih profesional dalam mengendalikan portofolio investasinya, sehingga lebih kecil kemungkinan mendapatkan informasi keuangan yang terdistorsi. Semakin besar prosentase saham yang dimiliki investor institusional akan menyebabkan pengawasan yang dilakukan menjadi lebih efektif karena dapat mengendalikan perilaku oportunistik manajer dan mengurangi agency cost (Nuraina, 2012). Kepemilikan institusional memiliki kemampuan untuk mengendalikan pihak manajemen melalui proses monitoring secara efektif sehingga dapat mengurangi manajemen laba. Persentase saham tertentu yang dimiliki oleh institusi dapat mempengaruhi proses penyusunan laporan keuangan yang tidak menutup kemungkinan terdapat akrualisasi sesuai kepentingan pihak manajemen (Boediono, 2005).

\section{Hipotesis 2 : Diduga kepemilikan institusional berpengaruh terhadap manajemen laba.}

Perusahaan yang berukuran besar memiliki peran sebagai pemegang kepentingan yang lebih luas. Hal ini membuat berbagai kebijakan perusahaan besar akan memberikan dampak yang besar terhadap kepentingan publik dibandingkan perusahaan kecil. Perusahaan yang besar lebih diperhatikan oleh masyarakat sehingga lebih berhati-hati dalam melakukan pelaporan keuangan. Menyebabkan perusahaan harus melaporkan kondisinya lebih akurat (Ningsaptiti, 2010). Tetapi, perusahaan berukuran besar cenderung mendapat tekanan-tekanan untuk memenuhi harapan pasar sehingga mereka terdorong untuk melakukan manajemen laba. Selain 
itu perusahaan besar juga memiliki "bargaining power" yang lebih besar untuk bernegosiasi dengan auditor untuk melakukan manajemen laba (Nanok, et.al).

Hipotesis 3 : Diduga ukuran perusahaan berpengaruh terhadap manajemen laba.

\section{METODOLOGI PENELITIAN}

\section{Variabel Penelitian}

Variabel Dependen dalam penelitian ini adalah manajemen laba pada perusahaan subsektor tekstil dan garmen di Bursa Efek Indonesia. Sedangkan Variabel Independennya adalah leverage, struktur kepemilikan institusional dan ukuran perusahaan.

\section{Manajemen Laba}

Manajemen laba dihitung dengan menggunakan Modified Jones Model.Manajemen laba diprosikan dengan discretionary accrual. Berikut tahap-tahap dalam menghitung manajemen laba (Sulistyanto, 2008) :

1. Menghitung Total Accrual. Total Accrual (TAC) = Net Income - Cash Flow from operating activities)

2. Menghitung Nilai Akrual dibandingkan total aset tahun sebelumnya. $T A C_{t} / A_{t-1}=a_{1}\left(1 / A_{t-1}\right)+a_{2}\left(\wedge R E C_{t} / A_{t-1}\right)+a_{3}\left(P P E_{t} / A_{t-1}\right)+e$

3. Bila sudah didapat koefisien $\boldsymbol{\alpha}_{1}, \boldsymbol{\alpha}_{2}, \boldsymbol{\alpha}_{3}$, kemudian koefisien-koefisien ini dimasukkan ke persamaan berikut ini, untuk menghitung non discretionary accruals (NDA) :

$N A_{t}=a_{1}\left(1 / A_{t-1}\right)+a_{2}\left(\left(\wedge R E V_{t}-\Lambda R E C_{t}\right) / A_{t-1}\right)+a_{3}\left(P P E_{t} / A_{t-1}\right)$

4. Menghitung discretionary accruals.

$\mathrm{DAC}_{t}=\left(\mathrm{TAC}_{t} / \mathrm{A}_{\mathrm{t}-1}\right)-\mathrm{NDA}_{\mathrm{t}}$

Net Income = Laba Bersih setelah pajak

Cash Flow from operating activities $=$ arus kas operasi

$\mathrm{TAC}_{\mathrm{t}} \quad=$ Total Accruals perusahaan i pada periode $\mathrm{t}$

$\mathrm{A}_{\mathrm{t}-1} \quad=$ Total Aset perusahaan i pada periode $\mathrm{t}-1$

$\triangle \mathrm{REC}_{\mathrm{t}} \quad=$ Perubahan piutang dari tahun $\mathrm{t}-1$ ke tahun $\mathrm{t}$

$\mathrm{PPE}_{\mathrm{t}} \quad=$ Aset Tetap pada tahun $\mathrm{t}$

$\mathrm{NDA}_{\mathrm{t}} \quad=$ Non discretionary accruals pada tahun $\mathrm{t}$

$\Lambda R E V_{t} \quad=$ Perubahan pendapatan dari tahun $\mathrm{t}-1$ ke tahun $\mathrm{t}$

$\mathrm{a}=$ = fitted coefficient yang diperoleh dari hasil regresi pada perhitungan total accruals

DAC $_{\mathrm{t}}=$ Discretionary Accrual pada tahun $\mathrm{t}$

Jika Discretionary Accrual hasilnya negatif, maka perusahaan melakukan manajemen laba dengan cara menurunkan laba. Bila nilainya positif, maka perusahaan melakukan manajemen laba dengan menaikkan laba.(Elfira, 2009)

\section{Leverage}

Rasio utang yang dipakai adalah Debt To Total Asset. Berikut rumusnya (Kasmir, 2008)

Debt to Total Asset $=\frac{\text { Total } \text { Debt }}{\text { Total Asset }}$ 


\section{Kepemilikan Institusional}

Struktur kepemilikan institusional adalah perbandingan antara jumlah lembar saham yang dimiliki oleh institusi dibandingkan dengan jumlah lembar saham yang beredar. Berikut rumusnya (Kusumawardhani, 2012)

INSTITUSIONAL $=\frac{\text { Jumlah lembar saham yang dimiliki insitusional }}{\text { Jumlah lembar saham beredar }}$

\section{Ukuran Perusahaan}

Ukuran perusahaan dalam penelitian ini diproksikan dengan total aset. Berikut rumusnya(Sudarmadji dan Sularto, 2007).

Ukuran Perusahaan $=$ Total Aset

\section{HASIL DAN PEMBAHASAN}

Dari 16 sampel perusahaan, dengan periode penelitian 3 tahun, maka didapat 48 data. Dari 48 data, ada 37 data yang manajemen labanya bernilai negatif. Sisanya 11 data bernilai positif. Berikut hasil-hasil yang lain.

Tabel 1 Satatistiki Deskriptif

Descriptive Statistics

\begin{tabular}{lrrrrr}
\hline & $\mathrm{N}$ & \multicolumn{1}{c}{ Minimum } & \multicolumn{1}{c}{ Maximum } & \multicolumn{1}{c}{ Mean } & \multicolumn{1}{c}{ Std. Deviation } \\
\hline MJLABA & 48 & -.5610273 & .3026738 & -.086143160 & .1471769472 \\
\hline INSTITUSI & 48 & 41.0000000 & 98.8500000 & $6.668177708 \mathrm{E} 1$ & $1.7297238869 \mathrm{E} 1$ \\
\hline TOTASET & 48 & .0500000 & 12.7300000 & 2.326458333 & $3.0988120508 \mathrm{E} 0$ \\
\hline DAR & 48 & .0000040 & .8538256 & .186962689 & .2792201744 \\
\hline Valid N (listwise) & 48 & & & & \\
\hline
\end{tabular}

Gambar 2 : Statistik Deskriptif

Dari statistik deskriptif, dapat dilihat bahwa kepemilikan institusional, minimal adalah $41 \%$. Sedangkan yang paling besar adalah mencapai $98,85 \%$. Untuk total aset minimal berukuran Rp.50 M, sedangkan yang paling besar adalah Rp.12,73 T. Untuk debt to asset ratio, yang paling kecil $0,0004 \%$, sedangkan maksimal adalah $85,38 \%$.

Tabel 2 Uji T (Parsial)

\section{Coefficients $^{\mathrm{a}}$}

\begin{tabular}{|c|c|c|c|c|c|c|}
\hline \multirow[t]{2}{*}{ Model } & & \multicolumn{2}{|c|}{$\begin{array}{l}\text { Unstandardized } \\
\text { Coefficients }\end{array}$} & \multirow{2}{*}{$\begin{array}{c}\begin{array}{c}\text { Standardized } \\
\text { Coefficients }\end{array} \\
\text { Beta }\end{array}$} & \multirow[t]{2}{*}{$t$} & \multirow[t]{2}{*}{ Sig. } \\
\hline & & $B$ & Std. Error & & & \\
\hline \multirow[t]{4}{*}{1} & (Constant) & -.049 & .088 & & -.554 & .583 \\
\hline & INSTITUSI & .000 & .001 & -.104 & -.745 & .460 \\
\hline & TOTASET & .015 & .007 & .324 & 2.280 & .027 \\
\hline & DAR & -.078 & .075 & -.148 & -1.033 & .307 \\
\hline
\end{tabular}

a. Dependent Variable: milaba 
Dari hasil uji $\mathrm{t}$, diketahui bahwa hanya total aset saja yang berpengaruh terhadap manajemen laba. Sedangkan kepemilikan institusional dan leverage tidak berpengaruh terhadap manajemen laba.

Tabel 3 Uji Simultan (Bersamaan)

ANOVA $^{\text {b }}$

\begin{tabular}{llccccc}
\hline \multirow{2}{*}{ Model } & & $\begin{array}{c}\text { Sum of } \\
\text { Squares }\end{array}$ & df & Mean Square & F & Sig. \\
\hline \multirow{3}{*}{1} & Regression & 0,162 & 3 & 0,054 & 2.773 & $0,048^{a}$ \\
\cline { 2 - 7 } & Residual & 0,856 & 44 & 0,019 & & \\
\cline { 2 - 7 } & Total & 1.018 & 47 & & & \\
\hline
\end{tabular}

a. Predictors: (Constant), institusi,totaset,dar

b. Dependent Variable: milaba

Dari hasil uji $\mathrm{F}$, secara simultan, kepemilikan institusional, total aset dan leverage berpengaruh terhadap manajemen laba. Leverage tidak berpengaruh terhadap manajemen laba. Besar kecilnya leverage tidak membuat perusahaan takut akan terjadinya debt default. Hal ini mungkin disebabkan bahwa utang akan dibayar sesuai dengan jatuh temponya. Ukuran perusahaan berpengaruh positif terhadap manajemen laba. Dari koefisien ukuran perusahaan bernilai 0,15 berarti bahwa setiap kenaikan ukuran perusahaan sebesar Rp.1, maka manajemen laba akan naik sebesar Rp.0,15. Hal ini berarti bahwa semakin besar perusahaan, semakin tinggi juga manajemen labanya. Perusahaan besar dalam mempertahankan eksistensinya, maka cenderung melakukan manajemen laba. Agar dipandang dari pihak luar, perusahaan yang baik.

Kepemilikan institusional tidak berpengaruh terhadap manajemen laba. Besar kecil struktur kepemilikan secara institusional, tidak mendorong institusi untuk melakukan manajemen laba. Hal ini karena pengawasan dari institusi yang lebih banyak dan kuat.

\section{Kesimpulan}

Berdasarkan hasil pengolahan data, maka kesimpulan dalam penelitian ilmiah ini adalah :

1. Leverage tidak berpengaruh terhadap manajemen laba.

2. Struktur kepemilikan insitusional tidak berpengaruh terhadap manajemen laba.

3. Ukuran perusahaan berpengaruh terhadap manajemen laba.

4. Leverage, struktur kepemilikan institusional dan ukuran perusahaan berpengaruh secara simultan terhadap manajemen laba.

\section{Daftar Pustaka}

Abdurrahim,"Mendeteksi Earning Management", Jurnal Akuntansi \& Investasi, Vol.1 no.2, ISSN : 1411-6227, hal.104-111.

Aditya (2014), "Pengaruh Kualitas Auditor, Debt to Asset dan Ukuran Perusahaan terhadap Manajemen Laba, Skripsi, Universitas Maritim Raja Ali Haji, Tanjungpinang. 
Aryati (2017), "Earning Management", Kuliah Umum, Universitas Maritim Raja Ali Haji, Tanjungpinang.

Boediono, G S. B. (2005), Kualitas Laba: Studi Pengaruh Mekanisme Corporate Governance dan Dampak Manajemen Laba dengan Menggunakan Analisa Jalur, Simposium Nasional Akuntansi VIII, Universitas Sebelas Maret, Surakarta. Dechow

Elfira (2009), "Pengaruh Kompensasi Bonus dan leverage terhadap Manajemen Laba", Skripsi, Universitas Negeri Padang.

Healy, Paul M, Wahlen, James M., (1999), A review of the Earnings Management Literature and Its Implications for Standard Setting, Accounting Horizons, December 1999, vol.13, no.4, pp.365-383.

Hery (2016), Analisis Laporan Keuangan", Grasindo, Jakarta

Indriani (2010), Pengaruh Kualitas Auditor, corporate governance, leverage, dan kinerja keuangan terhadap manajemen laba, skripsi, Universitas Diponegoro, Semarang.

Kasmir (2008), Analisis Laporan Keuangan, Rajawali Pers, 2008.

Kusumawardhani (2012), "Pengaruh Corporate Governance, Struktur Kepemilikan dan Ukuran Perusahaan terhadap Manajemen Laba, Jurnal Akuntansi dan Sistem Teknologi Informasi, vol.9, no.1, Oktober 2012,FE UPN "Veteran", Jogjakarta, hal.41-54.

Nanok, Natasya, Widadi, Faktor-faktor yang mempengaruhi manajemen laba perusahaan publik di Indonesia 2008", Journal of Applied Finance and Accounting, vol.3 no.1, UNIKa Atmajaya, Jakarta, hal.60-74.

Nuraina (2012), "Pengaruh Kepemilikan Institusional dan Ukuran Perusahaan terhadap kebijakan hutang dan nilai perusahaan", Jurnal Bisnis dan Ekonomi, vol.19, no.2,September 2012, IKIP PGRI, Madiun, hal.110-125.

Sudarmadji, Sularto (2007), "Pengaruh Ukuran Perusahaan, profitabilitas, leverage dan tipe kepemilikan perusahaan terhadap luas voluntary disclosure laporan keuangan tahunan", proceeding PESAT, vol.2.

Susanti, "Faktor-faktor yang mempengaruhi manajemen laba perusahaan perbankan 2009-2014", Universitas Pandaran, Semarang. 
Pengaruh Leverage, Kepemiikan Institusional

Dan Ukuran Perusahaan Terhadap Manajemen Laba

Hal. 44 